\title{
PELATIHAN DAN PENDAMPINGAN SERTIFIKASI PROFESI TEKNISI AKUNTANSI BAGI GURU AKUNTANSI DI KOTA MALANG
}

\author{
Makaryanawati $^{1}$, Eka Ananta Sidharta ${ }^{2}$, Ridoni Fardeni Harahap ${ }^{3}$, Rizka Furqorina ${ }^{4}$ \\ $1,2,3,4$ Universitas Negeri Malang \\ makaryanawati.fe@um.ac.id
}

\begin{abstract}
The globalization of the labor market led to increased labor competition in the country. The influx of foreign workers makes domestic workers have to prepare themselves to be able to compete competitively. To win the competition, the labor must have the competency certification required by labor users. This competency certification is issued by a competent certification body. Competency certification covers various fields, including competencies in the field of accounting, which has an important role in the company as the party responsible for preparing financial statements. The need for competency information underlies the Community Service team majoring in accounting to socialize how the mechanisms and techniques to obtain Accounting Technician competency certification. This socialization was packaged in a Webinar forum which invited 21 participants who are members of the Malang City Economics MGMP. This activity provides benefits, including providing solutions to improve the understanding and capabilities of Accounting Teachers, one of which is through training and mentoring by parties experienced in Accounting Technician Professional Certification; provide easy-to-understand training on Accounting Technician Professional Certification and provide tips and tricks for facing the Accounting Technician Competency Test; increase the motivation of the Accounting Teacher to provide training and understanding to students in preparing for the Accounting Technician Competency Test.
\end{abstract}

Keywords: LSP, accounting technician

\section{PENDAHULUAN}

Sejak menjadi bagian dari Masyarakat Ekonomi Asean (MEA), terdapat banyak tantangan sekaligus peluang yang dihadapi oleh Indonesia. Pada dasarnya pembentukan MEA ditujukan untuk membangun pasar tunggal dan basis produksi di Kawasan ASEAN (Inayati et al., 2010). Hal tersebut menyebabkan timbulnya kebebasan aliran modal, barang, jasa, investasi, dan tenaga kerja terampil bagi Negara-negara di Kawasan tersebut (Mulyana, 2016). Bergabungnya Indonesia dalam komunitas tersebut juga menuntut Indonesia untuk mengikuti kebijakan yang telah ditetapkan, salah satunya adalah adanya kebebasan arus tenaga kerja terampil yang masuk ke industri tenaga kerja Indonesia. Tenaga kerja terampil disini merupakan pekerja yang mempunyai keahlian, pengetahuan, maupun keterampilan khusus, yang diperoleh dari pendidikan formal maupun informal (Amallia, 2017). Adanya kebebasan tersebut kemudian menimbulkan persaingan tenaga kerja yang semakin kompetitif.

Saat ini situasi dalam negeri belum menguntungkan bagi para pencari kerja domestik. Berdasarkan hasil penilaian International Institute for Management Development (IMD) dalam World Competitiveness Ranking 2020, daya saing tenaga kerja Indonesia masih tertinggal dibandingkan dengan negara-negara di kawasan ASEAN seperti Thailand, Malaysia, dan Singapura (Putra, 2020). Hal tersebut disebabkan oleh Pendidikan pekerja domestik yang didominasi oleh lulusan SD ke bawah sebanyak 52,40 juta dan adanya ketidaksesuaian pendidikan dengan pekerjaan sebanyak 60,52\% (Katadata.com, 2019). Fakta tersebut diperparah dengan tingkat pengangguran sebesar $7,07 \%$ yang meningkat sebesar 1,84\% dibandingkan tahun sebelumnya (BPS, 2020).

Masuknya Tenaga Kerja Asing (TKA) ke Indonesia menciptakan persaingan kerja yang semakin ketat (Gumelar, 2018). Lulusan sebagai output lembaga pendidikan formal pada saat ini dan di masa yang akan datang harus bersaing dalam memperebutkan kesempatan 
kerja yang semakin kompetitif. Selain harus bersaing dengan rekan domestik yang seangkatan tetapi juga harus bertanding dengan tenaga kerja senior yang telah memiliki pengalaman kerja yang menjadi korban efisiensi perusahaan. Bahkan, juga harus bersaing dengan tenaga kerja manca negara yang pada umumnya telah memiliki sertifikasi kompetensi.

Di sisi lain perusahaan sebagai users dihadapkan pada banyak pilihan lulusan pendidikan dalam negeri yang kompetensinya tidak terdeskripsi secara jelas. Hal ini menyulitkan perusahaan dalam menyeleksi dan merekrut tenaga kerja domestik. Kadangkala keterampilan yang dimiliki angkatan kerja Indonesia tidak sesuai dengan keinginan Penanam Modal Asing (PMA) yang ada di Indonesia (Gumelar, 2018). Salah satu langkah yang perlu dilakukan untuk membantu lulusan domestik agar memiliki peluang yang lebih besar dalam memperoleh pekerjaan adalah dengan pembuktian kompetensi. Pembuktian kompetensi calon tenaga kerja menjadi penting karena dapat memberikan gambaran kepada perusahaan tentang kompetensi yang dimiliki tenaga kerja secara jelas, terukur, dan valid. Pembuktian atas kompetensi seseorang dapat diwujudkan dalam bentuk pemberian sertifikat oleh lembaga sertifikasi yang kompeten dan berhak mengeluarkannya.

Selain itu, kompetensi ini sudah diatur dalam sebuah standar yaitu, Kerangka Kualifikasi Nasional Indonesia (KKNI) yang dituangkan dalam Kepmen Nomor 43/MEN/III/2008 Tentang Penetapan Standar Kompetensi Kerja Nasional Indonesia, salinan Peraturan Menteri Tenaga Kerja dan Transmigrasi Republik Indonesia. KKNI merupakan kerangka penjenjangan kualifikasi sumber daya manusia Indonesia yang menyandingkan, menyetarakan, dan mengintegrasikan sektor pendidikan dengan sektor pelatihan dan pengalaman kerja dalam suatu skema pengakuan kemampuan kerja yang disesuaikan dengan struktur di berbagai sektor pekerjaan (Perpres No 8/2012/KKNI). KKNI merupakan perwujudan mutu dan jati diri bangsa Indonesia terkait dengan sistem pendidikan nasional, sistem pelatihan kerja nasional, dan sistem penilaian kesetaraan capaian pembelajaran (learning outcomes) nasional, yang dimiliki Indonesia untuk menghasilkan sumber daya manusia nasional yang bermutu dan produktif (Santoso et al., 2015). Dengan adanya sertifikasi dan dibarengi dengan keterampilan umum yang diperoleh serta kemudahan teknologi, lulusan akan lebih sukses di lingkungan profesional mereka (Asonitou \& Hassall, 2019).

Berdasarkan beragam permasalahan tersebut, program pengabdian masyarakat ini hadir sebagai solusi yang diberikan untuk membantu tenaga pendidik dalam melahirkan lulusan yang siap kerja dan bersaing dengan tenaga kerja domestik maupun asing. Pengabdian kepada masyarakat ini dilakukan oleh tim Pengabdian Fakultas Ekonomi Universitas Negeri Malang dengan partisipan Guru Akuntansi di Kota Malang. Tujuan Pengabdian kepada Masyarakat yang dilakukan adalah untuk memberikan pemahaman kepada Guru Akuntansi di Kota Malang tentang pentingnya sertifikasi profesi teknisi akuntansi serta tips untuk melatih siswa agar lulus sertifikasi Teknisi Akuntansi. Manfaat yang diperoleh dari kegiatan pengabdian ini adalah (1) memberikan solusi dalam meningkatkan pemahaman serta kapabilitas Guru Akuntansi, salah satunya dengan pelatihan serta pendampingan oleh pihak yang berpengalaman dalam Sertifikasi Profesi Teknisi Akuntansi; (2) memberikan pelatihan tentang Sertifikasi Profesi Teknisi Akuntansi yang mudah dipahami dan memberikan tips dan trik untuk menghadapi Uji Kompetensi Teknisi Akuntansi; (3) meningkatkan motivasi Guru Akuntansi untuk memberikan pelatihan dan pemahaman kepada siswa dalam mempersiapkan Uji Kompetensi Teknisi Akuntansi.

\section{METODE}

Upaya membantu meningkatkan pemahaman Guru Akuntansi di Kota Malang mengenai 
Sertifikasi Profesi Teknisi Akuntansi, maka kegiatan pengabdian ini dilaksanakan dalam forum pelatihan dan pendampingan. Alur kegiatan PKM bagi mitra Guru Akuntansi di Kota Malang dapat dilihat pada Gambar 1.

\section{PERENCANAAN}

\begin{tabular}{|c|c|c|}
\hline Analisis Situasi & Menyusun Proposal & $\begin{array}{c}\text { Menyusun rencana } \\
\text { kegiatan operasional }\end{array}$ \\
\hline & PELAKSANAAN \\
\hline Memberi Pelatihan \& Pendampingan tentang Sertifikasi Profesi Teknisi \\
Akuntansi di Kota Malang
\end{tabular}

\section{EVALUASI DAN PELAPORAN}

Menyusun laporan akhir

Gambar 1. Tahapan Kegiatan Pengabdian Kepada Masyarakat

Rangkaian kegiatan pengabdian masyarakat yang dilakukan oleh Tim PKM Jurusan Akuntansi FE UM adalah sebagai berikut:

1. Tahap Perencanaan

Tahap ini dimulai dengan menganalisis situasi permasalahan, kemudian menyusun dan mengajukan proposal kepada LP2M Universitas Negeri Malang untuk dievaluasi kelayakan dan pendanaan. Pada tahap ini terdiri dari:

1) penyiapan bahan administrasi sesuai dengan kebutuhan pelaksanaan sosialisasi

2) melakukan koordinasi dengan MGMP Akuntansi Kota Malang

3) menyiapkan materi pelatihan dan sarana prasarana yang mendukung pelatihan

4) menghubungi narasumber yang memiliki kompetensi sesuai dengan target dan tujuan pelatihan

5) menyiapkan jadwal pelatihan sesuai dengan perencanaan kegiatan yang telah terprogram

6) setelah proposal mendapat persetujuan dari Pimpinan LP2M Universitas Negeri Malang, selanjutnya menyusun Rencana Kegiatan Operasional (RKO).

2. Tahap Pelaksanaan

Tahap pelaksanaan kegiatan pengabdian ini adalah melakukan pelatihan/sosialisasi bagi Guru Akuntansi di Kota Malang yang tergabung dalam MGMP Akuntansi Kota Malang. Metode yang digunakan dalam pelatihan ini meliputi pemberian materi dan melakukan praktik mengenai penyusunan laporan keuangan serta pendampingan dalam penyusunan laporan keuangan. Pada tahap ini terdiri dari kegiatan sebagai berikut:

1) melakukan pelatihan sertifikasi profesi Teknisi Akuntansi bagi Guru Akuntansi.

2) diskusi mengenai pemahaman wawasan dan keterampilan yang sudah peserta kuasai \& tanya jawab.

3) praktik langsung bagi peserta dan pendampingan mengerjakan soal-soal praktik ujian.

\section{HASIL KARYA UTAMA DAN PEMBAHASAN}

\section{Gambaran Umum}


Globalisasi tenaga kerja yang sudah dimulai beberapa tahun terakhir ini menyebabkan kondisi memprihatinkan bagi calon tenaga kerja di dalam negeri. Persaingan untuk memperoleh pekerjaan sesuai bidangnya semakin ketat. Apalagi ditunjang dengan kondisi perekonomian saat ini yang semakin melemah. Banyak perusahaan yang harus mengefisienkan tenaga kerja, yang berdampak pada peningkatan jumlah pengangguran di negeri ini. Kondisi ini menuntut tenaga kerja domestik harus mempersiapkan diri agar dapat memenangkan persaingan dengan tenaga kerja asing dalam memperebutkan peluang kerja di dalam negeri maupun di luar negeri.

Disamping itu, perusahaan sebagai pihak yang akan menggunakan tenaga kerja dihadapkan pada banyak pilihan lulusan pendidikan dalam negeri yang kompetensinya tidak terdeskripsi secara jelas. Hal ini menyulitkan perusahaan dalam proses perekrutan dan penyeleksian tenaga kerja domestik. Salah satu cara yang dapat dilakukan oleh para lulusan domestik untuk dapat memperoleh kesempatan mendapatkan pekerjaan yang sesuai dengan bidangnya adalah memiliki sertifikasi kompetensi.

Sertifikasi kompetensi akan diperoleh setelah dinyatakan lulus uji kompetensi yang dilaksanakan di Tempat Uji Kompetensi (TUK). Mulai tahun 2019, Jurusan Akuntansi Fakultas Ekonomi Universitas Negeri Malang dipercaya sebagai Lembaga yang dapat menyelenggarakan Uji Kompetensi Teknisi Akuntansi. Dengan demikian, tim pelaksana pengabdian masyarakat FE UM berkewajiban untuk memberikan pemahaman kepada masyarakat mengenai sertifikasi kompetensi dan mensosialisasikan TUK yang berada di lingkungan Universitas Negeri Malang.

\section{Kegiatan Pelatihan dan Pendampingan Profesi Teknisi Akuntansi}

Kegiatan pengabdian masyarakat mengenai pelatihan dan pendampingan sertifikasi profesi Teknisi Akuntansi diawali dengan tahap perencanaan, yaitu menganalisis situasi permasalahan yang terjadi berkaitan dengan kompetensi yang dimiliki masyarakat usia kerja. Selanjutnya mengajukan proposal kepada LP2M Universitas Negeri Malang untuk dievaluasi kelayakan dan pendanaan. Tahap ini meliputi penyiapan bahan administrasi sesuai kebutuhan pelaksanaan sosialisasi, melakukan koordinasi dengan Guru-guru yang tergabung dalam MGMP Akuntansi Kota Malang, menyiapkan materi pelatihan dan sarana prasarana yang mendukung pelatihan, menghubungi narasumber yang memiliki kompetensi sesuai dengan target dan tujuan pelatihan, menyiapkan jadwal pelatihan sesuai dengan perencanaan kegiatan yang telah terprogram.

Tahap berikutnya adalah pelaksanaan, dengan menyelenggarakan pelatihan dan pendampingan sertifikasi profesi Teknisi Akuntansi bagi Guru Akuntansi melalui platform Zoom Meeting. Pelaksanaan pelatihan ini diawali dengan pemaparan materi. Peserta yang mendaftar untuk mengikuti pelatihan sebanyak 21 orang yang berasal dari komunitas MGMP Akuntansi di Kota Malang. Pelatihan dilaksanakan pada hari Sabtu, 19 September 2020 pukul 09.00 - selesai. Pada kegiatan ini materi disampaikan oleh Dr. Murtanto, SE., MSi., Ak., CA selaku Asesor dan Master Asesor dan Adi Firman Ramadhan, SE., MAk., Ak., CA., CAAT. Pemateri pertama menyampaikan materi tentang pentingnya sertifikasi Teknisi Akuntansi dan bagaimana tahapan yang harus dilakukan untuk memperoleh sertifikasi Teknisi Akuntansi. Sedangkan pemateri kedua menyampaikan materi tentang pelatihan dan tips dalam mennyelesaikan soal-soal sertifikasi Teknisi Akuntansi. Setelah pemaparan materi, dilanjutkan dengan diskusi mengenai pemahaman wawasan dan keterampilan yang sudah peserta kuasai dan tanya jawab. Tahap ini diakhiri dengan praktik langsung bagi peserta dan pendampingan mengerjakan soal-soal praktik ujian. Dokumentasi sosialisasi dan pemberian materi dapat dilihat di Gambar 2. 


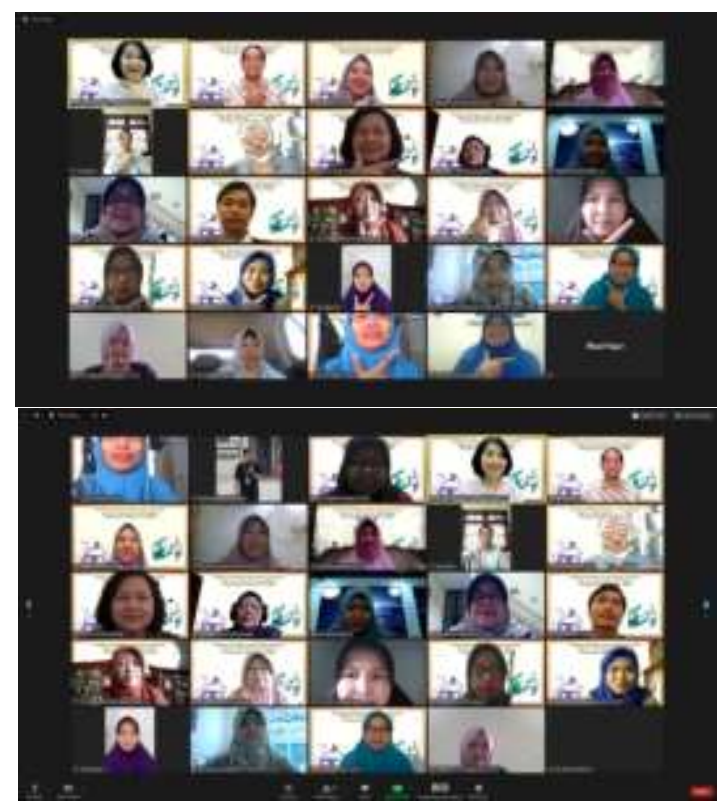

Gambar 2. Kegiatan Sosialisasi dan Pemberian Materi

\section{Pembahasan}

Sertifikasi kompetensi merupakan sertifikasi yang sangat penting karena dapat memberikan gambaran mengenai kemampuan dan kewenangan yang dimiliki oleh seseorang untuk melakukan suatu pekerjaan, yang didasari oleh pengetahuan, keterampilan dan sikap sesuai dengan unjuk kerja yang ditetapkan. Demikian halnya dengan sertifikasi kompetensi Teknisi Akuntansi. Sertifikasi ini sangat diperlukan, karena dapat menggambarkan kemampuan dan keterampilan seseorang dalam menyelesaikan pekerjaan terkait dengan bidang akuntansi. Sertifikasi Teknisi Akuntansi dibagi dalam 25 unit kompetensi, antara lain Menerapkan Prinsip Praktik Profesional dalam bekerja, Menyusun Laporan Keuangan, Mengoperasikan Aplikasi Komputer Akuntansi, Mengelola Kartu Piutang, Menyiapkan Kartu Persediaan, Menyiapkan Kartu Aktiva Tetap, Menyiapkan Laporan Harga Pokok Produksi, Menyiapkan Surat Pemberitahuan Pajak, Menyajikan Informasi Akuntansi Manajemen, dan Melaksanakan Proses Pemeriksaan Informasi Keuangan.

Pada pelatihan dan pendampingan sertifikasi kompetensi Teknisi Akuntansi yang diselenggarakan Tim PKM Jurusan Akuntansi FE UM hanya memfokuskan pada unit kompetensi Menyusun Laporan Keuangan. Setiap unit kompetensi diterjemahkan ke dalam beberapa elemen kompetensi, selanjutnya setiap elemen kompetensi dapat diukur dalam beberapa kriteria unjuk kerja. Berikut elemen kompetensi dan kriteria unjuk kerja yang ditetapkan dalam unit kompetensi Menyusun laporan keuangan.

Tabel 1. Elemen Kompensi dan Kriteria Unjuk Kerja

\begin{tabular}{|l|l|}
\hline \multicolumn{1}{|c|}{ ELEMEN KOMPETENSI } & \multicolumn{1}{c|}{ KRITERIA UNJUK KERJA } \\
\hline Mencatat jurnal penyesuaian & $\begin{array}{l}\text { 1. Dokumen sumber penyesuaian disediakan } \\
\text { 2. Akun-akun yang memerlukan penyesuaian } \\
\text { diidentifikasi }\end{array}$ \\
& $\begin{array}{l}\text { 3. Jurnal penyesuaian yang diperlukan dicatat } \\
\text { Menyajikan laporan }\end{array}$ \\
& $\begin{array}{l}\text { 2. Neraca lajur disiapkankan sesuai ketentuan SOP } \\
\text { Laporan laba rugi disajikan sesuai ketentuan }\end{array}$ \\
& $\begin{array}{l}\text { 3. Laporan laporan posisi keuangan disajikan sesuai } \\
\text { ketentuan SOP/SAK./SAK ETAP }\end{array}$ \\
& $\begin{array}{l}\text { 4aporan Perubahan ekuitas disajikan sesuai } \\
\text { ketentuan SOP/SAK/SAK ETAP }\end{array}$ \\
\hline
\end{tabular}




\begin{tabular}{|l|l|}
\hline & $\begin{array}{l}\text { 5. Laporan arus kas disajikan sesuai ketentuan } \\
\text { SOP/SAK/SAK ETAP }\end{array}$ \\
\hline Mencatat jurnal penutup & $\begin{array}{l}\text { 1. Akun yang didebit dan dikredit diidentifikasi } \\
\text { 2. Jurnal penutup dicatat }\end{array}$ \\
\hline $\begin{array}{l}\text { Memposting jurnal penyesuaian dan } \\
\text { jurnal penutup ke buku besar }\end{array}$ & $\begin{array}{l}\text { 1. Jurnal penyesuaian dan jurnal penutup diposting } \\
\text { 2. Saldo dalam buku besar setelah tutup buku } \\
\text { disajikan sesuai ketentuan SOP }\end{array}$ \\
\hline
\end{tabular}

Pada kegiatan ini, selain pemberian materi terkait gambaran umum sertifikasi Teknisi Akuntansi, pemateri juga memberikan tips dan trik cara pengerjaan soal-soal ujian sertifikasi kompetensi. Kegiatan ini juga dilengkapi dengan sesi tanya jawab seputar permasalahan yang sering terjadi pada saat ujian kompetensi dan pendampingan pengerjaan soal-soal uji kompetensi.

Setelah mengikuti kegiatan ini, terdapat beberapa manfaat yang diperoleh peserta, antara lain yaitu mengetahui Tempat Uji Kompetensi yang ada di FE UM, memahami pentingnya sertifikasi kompetensi bagi lulusan, memahami cara efektif dalam menyelesaikan ujian sertifikasi kompetensi dan termotivasi untuk memberikan materi kepada peserta didiknya, sesuai dengan Instruksi Presiden (Inpres) Nomer 9 tahun 2016 tentang Revitalisasi SMK untuk mempercepat sertifikasi kompetensi bagi lulusan, peserta didik dan tenaga pendidik SMK. Selain itu, adanya kegiatan pengabdian ini dapat meningkatkan link and match antara penyediaan tenaga kerja yang kompeten dengan kebutuhan industri, dunia usaha dan dunia kerja (IDUKA).

\section{KESIMPULAN}

Pelaksanaan kegiatan pengabdian masyarakat yang dilakukan oleh Tim PKM Jurusan Akuntansi FE UM berjalan dengan baik dan mendapatkan respon positif dari peserta. Hal ini terlihat pada antusiasme peserta ketika mengikuti pemaparan materi dan pelatihan serta pendampingan penyelesaian latihan soal uji kompetensi Teknisi Akuntansi. Disamping itu, peserta masih antusias berkomunikasi melalui whatsapp group, menanyakan mengenai tindak lanjut kegiatan sosialisasi tersebut. Peserta menginginkan adanya sinergi antara MGMP Akuntansi Kota Malang dengan Fakultas Ekonomi Universitas Malang dalam meningkatkan jumlah peserta didik yang memiliki sertifikasi kompetensi Teknisi Akuntansi, guna menunjang kapabilitas peserta didik dalam menghadapi persaingan tenaga kerja yang sangat kompetitif.

Berdasarkan hasil evaluasi atas kegiatan sosialisasi Sertifikasi Profesi Kompetensi Teknisi Akuntansi, maka disarankan agar kegiatan serupa dilaksanakan secara berkala dan diselenggarakan dengan mengundang berbagai komunitas yang berkepentingan. Hal ini dirasa sangat penting, mengingat Fakultas Ekonomi Universitas Negeri Malang sudah memiliki Tempat Uji Kompetensi, yang tentunya berkewajiban dalam memberikan pemahaman kepada masyarakat mengenai pentingnya sertifikasi kompetensi dan memberikan pengetahuan mengenai cara atau teknik agar dapat lulus uji kompetensi.

\section{UCAPAN TERIMA KASIH}

Ucapan terima kasih Tim Pengabdian Kepada Masyarakat (PKM) kepada Fakultas Ekonomi Universitas Negeri Malang yang telah mensupport segala kebutuhan dan memfasilitasi Tim PKM dalam melaksanakan pengabdian kepada masyarakat ini. Selain itu, Tim PKM juga mengucapkan terimakasih kepada Forum MGMP Akuntansi Kota Malang yang telah berkenan menjadi mitra dalam kegiatan pengabdian kepada masyarakat.

\section{DAFTAR PUSTAKA}


Amallia, B. (2017). DAMPAK ASEAN ECONOMIC COMMUNITY (AEC) TERHADAP TENAGA KERJA INDONESIA DI SINGAPURA. JOM FISIP, 4(2), 1-14.

Asonitou, S., \& Hassall, T. (2019). Which skills and competences to develop in accountants in a country in crisis? International Journal of Management Education, 17(3), 100308. https://doi.org/10.1016/j.ijme.2019.100308

BPS. (2020). [REVISI per 23/1 1/2020] Agustus 2020: Tingkat Pengangguran Terbuka (TPT) sebesar 7,07 persen. Badan Pusat Statistik. https://www.bps.go.id/pressrelease/2020/11/05/1673/agustus-2020--tingkatpengangguran-terbuka--tpt--sebesar-7-07-persen.html

Gumelar, G. (2018). Agar Lapak Pekerja Lokal Tak "Direbut" Tenaga Kerja Asing. CNN Indonesia. $\quad$ https://www.cnnindonesia.com/ekonomi/20180314094259-532282822/agar-lapak-pekerja-lokal-tak-direbut-tenaga-kerja-asing

Inayati, R. S., Elisabeth, A., Luhulima, C., Dewi, Anwar, F., Pudjiastuti, T. N., Muna, M. R., \& Sinaga, L. C. (2010). Piagam ASEAN Perkembangan Isu Demokrasi dan Hak Asasi Manusia (HAM). LIPI Press.

Katadata.com. (2019). Daya Saing Tenaga Kerja Indonesia Masih Tertinggal. Katadata.Com. katadata.co.id/timpublikasikatadata/infografik/5e9a51914fa52/daya-saing-tenagakerja-indonesia-masih-tertinggal

Mulyana, A. (2016). KEBIJAKAN PEMERINTAH DALAM MENGHADAPI MASYARAKAT EKONOMI ASEAN (MEA): SEBUAH TINJAUAN HAM. Jurnal Wacana Kinerja, 19(1), 60-88.

Putra, N. E. (2020). LM FEB UI Umumkan Daya Saing Indonesia 2020. Fakultas Ekonomi Dan Bisnis Universitas Indonesia. https://www.feb.ui.ac.id/blog/2020/07/18/lm-feb-uiumumkan-daya-saing-indonesia-2020/

Santoso, M., Putra, A., Muhidong, J., Sailah, I., Mursid, S., Rifandi, A., Susetiawan, \& Endrotomo. (2015). KERANGKA KUALIFIKASI NASIONAL INDONESIA (Y. Baso (ed.)). Direktorat Jendral Pembelajaran dan Kemahasiswaan Kementerian Riset, Teknologi, dan Pendidikan Tinggi Republik Indonesia. 